\title{
Assessment of exposure to environmental pollutants
}

\author{
David Coggon
}

\section{(Occup Environ Med 1995;52:562-564)}

Keywords: assessment; environment; exposure; pollution

Environmental hazards to health have a high public profile, but assessment of the risks that they pose is not easy. What is the morbidity, if any, caused by living near a hazardous waste incinerator? Do oestrogenic alkylphenolic pollutants in drinking water affect reproductive function, and if so, how much? Such questions have important implications for public health policy, but epidemiologists find them hard to answer.

One difficulty is the need to detect risks that are only marginally increased. In the occupational setting, uncertainties about low levels of risk can often be tolerated. We accept that many jobs carry a toll of injury or illness, provided that the risks are small and are controlled as far as is reasonably practical. The same levels of risk are not acceptable when the cause is pollution of the general environment. For one thing such pollution affects many more people, including potentially vulnerable groups such as children, pregnant mothers, and elderly people. Also, people are thought to have more choice about the job that they do than about the general environment to which they are exposed. The problem for the epidemiologist is that, even with large studies, small increases in risk are difficult to disentangle from the effects of bias and uncontrolled confounding.

Another major limitation is the lack of reliable information about people's exposure to environmental pollutants. Many epidemiological investigations rely on proxy measures of exposure such as distance of residence from a point source of pollution, but do not assess their validity. Techniques for measuring personal exposures in the workplace are now relatively well developed, but they have not been applied so widely in environmental studies. When errors in the assessment of exposure are unrelated to health outcome (as is most often the case) the effect is to attenuate risk estimates, and make hazards more difficult to detect.

In response to these problems, the Medical Research Council (MRC) convened a working group at the end of 1993 to examine ways of improving the assessment of environmental exposures, and to help formulate its research strategy on environmental pollution. The group focused on chemical pollutants, although many of its conclusions could be applied also to physical and biological hazards. It identified three main needs.

\section{Determinants of personal exposure and dose}

Firstly, and most importantly, was the requirement for more research into the determinants of personal exposure to environmental pollutants and the resultant dose of toxins to target tissues. People's exposure to pollutants can be monitored at a series of levels (table). With progression through this sequence, associations with disease outcomes become stronger. For example, health effects are more closely related to individual uptake of pollutants than to their concentrations in soil and water. The early stages of the sequence are important in that they offer a more practical basis for regulatory controls. It would be difficult to set standards for environmental pollutants based on personal exposures or biological monitoring.

There is a need, therefore, for better understanding of how the stages listed in the table interrelate. For example, what is the relative importance of indoor and outdoor sources of $\mathrm{NO}_{2}$ in determining personal exposures to the compound? The answer to this question will depend not only on the concentrations of $\mathrm{NO}_{2}$ in indoor and outdoor air but also on the times that people spend in these different environments. If indoor levels are more important, then how much are these influenced by the different sources of $\mathrm{NO}_{2}$ in buildings, such as gas cookers and fires? Does it make a big difference if a cooker has a pilot light? To resolve these questions, we

Levels at which environmental pollution can be measured

1 Release of pollutants into the environment-for example, the amount of a chemical discharged to water.

2 Concentrations of pollutants in one or more phases of the environment (soil, air, water, food)

3 Individual exposure to pollutants through inhalation, skin contact, and ingestion.

Individual uptake or dose of pollutants (what gets into the body as a result of exposure).

5 Amounts of pollutants reaching and interacting with targe organs or systems in the body. 
need epidemiological studies with personal exposures rather than disease as their outcome measure. Such studies are eminently feasible, given that passive sampling methods for personal monitoring of $\mathrm{NO}_{2}$ are cheap and readily available, ${ }^{1}$ and in the future it is likely that reliable methods will be developed for measuring short term peaks as well as longer term average exposures.

Information from this type of study will help to identify the most effective control strategies when risks need to be reduced. Also, it may even obviate the need for more difficult epidemiological studies with disease as an end point. For example, concerns have been raised about a possible risk of leukaemia from exposure to benzene in people living near petrochemical works. ${ }^{2}$ But a large survey from the United States, in which personal uptake of benzene was assessed by analysis of exhaled breath, suggested that living near refineries has little if any influence on dose. ${ }^{3}$ Much more important was whether subjects smoked cigarettes (levels in smokers were five times those in non-smokers), whether they lived with a smoker, how often they filled their car with petrol and whether they spent a lot of time driving in heavy traffic. If this is correct, then large scale epidemiological studies of leukaemia near refineries cannot be justified on the basis of suspicions about benzene.

Similarly, there are worries about possible risks of liver cancer and other malignancies from exposure to dioxins in people living near incinerators. The question is critical to planning policy, given that alternative methods of waste disposal such as landfill may also be hazardous. Geographical analyses of cancer incidence and mortality in the vicinity of incinerators are difficult to interpret because residents of such areas may differ from the general population in their drinking and smoking habits and in many other ways that affect their susceptibility to cancer. Even after adjustment for socioeconomic variables, it is hard to exclude the possibility of residual confounding as an explanation for small increases in risk. The solution to this problem might well come from studies to find out what are the major determinants of dioxin uptake in the general population, and particularly whether residence close to an incinerator is an important influence. If it is unimportant, then the need for studies of cancer incidence is less pressing.

Another value of studying the determinants of personal exposure and uptake of pollutants is the potential for improving assessment of exposures in epidemiological studies that cannot make direct use of personal monitoring, for example because it would be too expensive to carry out in the full population under study, or because the exposures of relevance are historical. If the important influences on exposure are known, then information about these variables can be collected, by questionnaire or other means, and used to derive a proxy index of exposure.

An exciting advance in recent years has been the development of techniques for mea- suring DNA adducts in people exposed to genotoxic carcinogens. ${ }^{4}$ Adducts form when such compounds or their metabolites interact with nucleophilic sites in DNA, and if not repaired can induce gene mutation, perhaps thus initiating carcinogenesis. Adducts are also formed with proteins such as haemoglobin, and although they are not thought to be as relevant to the carcinogenic process as DNA adducts, these too can be measured.

The analysis of adduct formation has three potential applications in the study of environmental carcinogens. Firstly, DNA and haemoglobin adducts may provide a measure of personal exposure that can be related to subsequent cancer incidence. Secondly, DNA adducts may serve as a proxy measure of disease outcome, eliminating some of the problems that occur in the investigation of carcinogens with a long latency. And thirdly, differences in propensity to form adducts when exposed to a carcinogen at a given level may distinguish people with unusual susceptibility to the hazard. If so, epidemiological studies restricted to such people might identify risks more clearly.

As yet, the scope for these applications is unclear. We need to know how closely adduct formation reflects personal exposure, how much variation in adduct formation occurs in people with similar exposures, what factors contribute to this variation between people, and how it relates to subsequent risk of cancer. A number of studies that answer the first three questions have been reported or are currently in progress, but answers to the last will require a bigger investment and will take longer to achieve.

Research in this area needs effective collaboration between epidemiologists, hygienists, and molecular biologists, and study designs must allow for the limited scale on which some of the assays for adduct formation can currently be carried out. For example, when looking at adduct formation as a risk factor for cancer, nested case-control designs with prospectively stored blood samples may be particularly appropriate. The validity of assays in stored specimens will first need to be established. In the long term, it should be possible to automate laboratory procedures that will be widely used.

\section{Sampling procedures}

The two other needs identified by the MRC's working group are more mundane, but nevertheless important. The first is the requirement for more attention to sampling procedures when measuring environmental pollutants. Differences in sampling strategies can have a major impact on the concentrations of pollutants that are found. For example, when measuring concentration of oxides of nitrogen in outdoor air, the positioning of samplers relative to roads can make a big difference to results. ${ }^{5}$ As yet there is no general agreement on where samplers should be placed. Similarly, the distribution of pollutants in soil can be very localised - for example, concentrations 
of chlorinated solvents may be increased immediately next to a leaking drum on a waste disposal site-and the spatial distribution and depth of sampling points can have a profound influence on measured concentrations. Also, the methods of storing and treating samples before analysis can introduce further variability.

In some cases it may be possible to standardise sampling procedures. For example, in the routine monitoring of drinking water that is currently carried out in Britain, samples are collected according to a standard protocol, both at water treatment plants and at the tap. In other cases - for example, measurement of pollutants in soil-the optimal sampling strategy will depend on the study question. In either situation, however, the methods of sampling and of storing and transporting samples should be adequately documented so that results can be properly interpreted and compared with those from other studies.

\section{Quality assurance}

The third major need is for better quality assurance of environmental exposure measurements. At present quality assurance in this field is not as well developed as it is, for example, in clinical chemistry, which could well serve as a model for good practice. Elements of a quality assurance programme should include observance of documented protocols and standardised procedures, not only for sampling and storage of specimens but also for their analysis in the laboratory; internal quality control, for example, through the use of "quality control samples" at regular intervals; and external quality assessment schemes, or if these are not available-for example, for very specialised analyses such as assays of DNA adducts-checks on accuracy with certified reference materials.

It is intended that the working group's report will help the MRC to formulate its research strategy on environmental pollution, and assist the research community by indicating some of the priorities for future investigation. Proposals for studies to examine the determinants of personal exposure and uptake of pollutants, and the potential of DNA adducts as markers of uptake or proxies for disease outcome, or both, are clearly important. Also, research proposals should pay due attention to sampling methods and quality assurance of assays.

Full copies of the working group's report are available on Full copies of the working group's report are available on Crescent, London WIN 4AL. The working group was established under the auspices of the MRC Committee on Toxic Hazards in the Environment and Workplace (Chairman Dame Barbara Clayton). The members of the group were Dr D Coggon (Chairman), Dr B Brown, Mr J Cherrie, Dr P B Farmer, Mr J K Fawell, Dr A Lovett, Dr D Gompertz, Dr P Harrison, Dr C W Suckling, Dr D Tennant, Dr A Wadge, Dr K J Finney, Mr K Brennan, and Dr G Sarna.

1 Raw GJ, Coward SKD. Exposure to nitrogen dioxide in homes in the UK: a pilot study. Proceedings of "unhealthy housing. the public health response." Warwick: Warwick University, 1991 .

2 Knox EG. Leukaemia clusters in childhood: geographical analysis in Britain. $\mathcal{f}$ Epidemiol Community Health 1994;48:369-76.

3 Wallace LA. The exposure of the general population to benzene. Cell Biol Toxicol 1989;5:297-314.

4 Hemminki K, Dipple A, Shuker DEG, Kadlubar FF, Segerbäck D, Bartsch H. DNA adducts: identification and Segerbacal Dignificance. Lyon: International Agenon and biological significance. Lyon: International Agency for

5 Quality of Urban Air Review Group. Urban air quality in the United Kingdom. London: QUARG, 1993.

\section{Vancouver style}

All manuscripts submitted to Occup Environ Med should conform to the uniform requirements for manuscripts submitted to biomedical journals (known as the Vancouver style.)

Occup Environ Med, together with many other international biomedical journals, has agreed to accept articles prepared in accordance with the Vancouver style. The style (described in full in the $B M F, 24$ February $1979, \mathrm{p} 532$ ) is intended to standardise requirements for authors.

References should be numbered consecutively in the order in which they are first mentioned in the text by Arabic numerals above the line on each occasion the reference is cited (Manson ${ }^{1}$ confirmed other reports $^{2-5}$. . .). In future references to papers submitted to Occup Environ Med should include: the names of all authors if there are seven or less or, if there are more, the first six followed by et al; the title of journal articles or book chapters; the titles of journals abbreviated according to the style of Index Medicus; and the first and final page numbers of the article or chapter. Titles not in Index Medicus should be given in full.

Examples of common forms of references are:

1 International Steering Committee of Medical Editors, Uniform requirements for manuscripts submitted to biomedical journals. Br Med f 1979;1:532-5.

2 Soter NA, Wasserman SI, Austen KF. Cold urticaria: release into the circulation of histamine and eosinophil chemotactic factor of anaphylaxis during cold challenge. N Engl $\Im$ Med 1976;294:687-90.

3 Weinstein L Swartz MN. Pathogenic properties of invading micro-organisms. In: Sodeman WA Jr, invading micro-organisms. In: Sodeman WA Jr, of disease. Philadelphia: W B Saunders, 1974:457-72. 